Full length Article

\title{
Intensifying ethanol production from brewer's spent grain waste: Use of whole slurry at high solid loadings
}

\author{
Tânia Pinheiro ${ }^{1}$, Eduardo Coelho ${ }^{1}$, Aloia Romaní, Lucília Domingues* \\ CEB - Centre of Biological Engineering, University of Minho, Campus Gualtar, 4710-057 Braga, Portugal
}

\section{A R T I C L E I N F O}

\section{Keywords:}

Brewer's spent grain waste

Whole slurry

High gravity ethanol

Autohydrolysis

Industrial strains

\begin{abstract}
A B S T R A C T
This work targets the valorization of brewer's spent grain (BSG) waste by ethanol production, providing strategies for increasing titers in the multiple process steps involved. High solid loadings and use of whole slurry from the pretreatment were evaluated, aiming to achieve high ethanol concentration and yield. As variability in BSG chemical composition presents a challenge for their valorization, six different BSGs were chemically characterized, which allowed the selection of two with high polysaccharide content. High solid loadings (up to 25\%) were employed for the pretreatment of selected BSGs by autohydrolysis, an environmentally friendly process, to improve enzymatic saccharification and extract fermentable sugars as oligosaccharides and monosaccharides. As a result, high glucose concentrations (43.7 and $57.7 \mathrm{~g} \mathrm{~L}^{-1}$ ) and glucose yield (85.9 and $70.6 \%$ ) were obtained from the saccharification of the pretreated BSG whole slurry at 20 and $25 \%$ solid loading, respectively. Whole slurries from autohydrolysis were used as substrate for ethanol production by hybrid saccharification and fermentation. Two different Saccharomyces cerevisiae strains were evaluated and high ethanol concentration $\left(42.27 \mathrm{~g} \mathrm{~L}^{-1}\right)$ at a high yield $(94.0 \%)$ was achieved. The results attained by the combined intensification approaches qualify BSG waste as a valuable renewable resource for cost-effective ethanol production.
\end{abstract}

\section{Introduction}

Brewer's spent grain (BSG) is a solid waste generated in large amounts (20 kg per $100 \mathrm{~L}$ of beer produced) [1] during the mashing process and represents about $85 \%\left(\mathrm{w} \mathrm{w}^{-1}\right)$ of brewing industry byproducts [2]. Breweries in Europe generate around 3.5 million tons of BSG per year [3]. Overall, BSG is a lignocellulosic biomass, which comprises $\sim 15-27 \%$ lignin, $12-25 \%$ cellulose, $19.2-41.9 \%$ hemicellulose, and $14-31 \%$ protein on a dry weight basis [3-9]. Thus, BSG has the potential to serve as a no/low cost raw material from which to produce ethanol, due to its high percentage of fermentable sugars and nitrogen source (not requiring addition of commercial nutrients) as well as availability throughout the year.

During the past years, studies have been carried out focusing on the valorization of BSG as a substrate for ethanol production. Alkali, acid or hydrothermal pretreatments are usually performed to deconstruct the lignocellulosic matrix and enable access to sugars in the cellulosic fraction [9-14]. Applying such strategies, it has been possible to achieve ethanol concentrations ranging from 4.3 to $22.0 \mathrm{~g} \mathrm{~L}^{-1}$, with yields between $23 \%$ and $81 \%$ [9-17]. Such values are considered insufficient when envisaging bioethanol production. In fact, a concentration of ethanol higher than $4 \%\left(\mathrm{w} \mathrm{w}^{-1}\right)$ is required to reduce energy consumption and make the distillation process feasible [18]. To attain such ethanol concentrations, the use of solid loadings above $15 \%$ $\left(\mathrm{w} \mathrm{v}^{-1}\right)$ is mandatory $[19,20]$. However, operating at high solid loadings (also known as high-gravity technology) is a challenge in bioethanol production, due to mass transfer limitations which can negatively affect process efficiency [18]. Moreover, high solid loadings can lead to higher enzyme activity losses due to difficulties in adsorption to the solid, hurdles in the dispersion of hydrolysis products causing enzyme inhibition by substrate, in addition to water availability constraints. Overall, these limitations may lead to a drop in the conversion efficiency of cellulose to glucose [21]. One way to overcome these drawbacks is the introduction of a high temperature saccharification stage prior to the traditional simultaneous saccharification and fermentation (SSF) process, which promotes liquefaction of the broth and

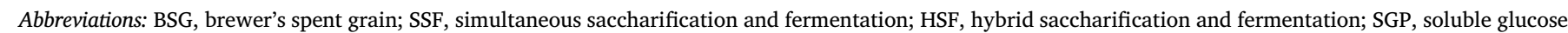

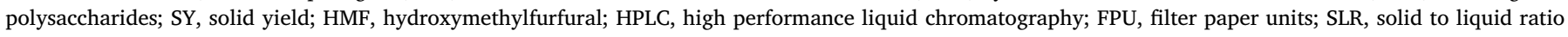

* Corresponding author.

E-mail address: luciliad@deb.uminho.pt (L. Domingues).

${ }^{1}$ Co-authorship as first authors. 
makes the mixing process easier [22]. This process configuration is also known as hybrid saccharification and fermentation (HSF) [23,24]. Besides exploring operation at high solid loadings, ethanol production from BSG must use all the sugar rich fractions as substrate and maintain high process efficiencies throughout the unit operations. Use of whole slurry (liquid + solid) allows a decrease in the overall water consumption and an increase in the sugar concentration available for fermentation [25]. These strategies can all be combined to reach the ultimate goal of high gravity ethanol production from lignocellulosic residues, where final ethanol concentrations exceeding $40-50 \mathrm{~g} \mathrm{~L}^{-1}$ are envisaged [26].

In this work, 6 BSG wastes from a craft brewery were characterized in order to assess their composition and screened for the best raw material for bioethanol production. Selected BSGs were treated by autohydrolysis at mild pretreatment temperatures and high solid loadings, for the improvement of enzymatic saccharification aiming at high sugar titers. Finally, whole slurry from BSG pretreatment was fermented by HSF using two Saccharomyces cerevisiae strains: a high gravity brewing yeast and a yeast isolated from bioethanol industry.

\section{Materials and methods}

\section{Raw material}

Six lots of BSG obtained from different beer types were supplied by Fermentum Lda., a local craft brewery (Vila Verde, Portugal). BSGs were in a wet-form with a moisture content of about $75 \%$ and were dried in an oven at $60{ }^{\circ} \mathrm{C}$ to reach a moisture content under $10 \%$. The feedstock material was then stored in sealed containers until required for processing or analysis.

\section{Chemical characterization of BSG}

The composition of the raw material was analyzed according to standard methods as described by the National Renewable Energy Laboratory (NREL) [27]. Ash content (NREL/TP-510-42622) was determined by weight difference before and after incineration of an aliquot of the material in a muffle furnace at $550{ }^{\circ} \mathrm{C}$ for $24 \mathrm{~h}$. Before weighing, samples were placed in a desiccator for $1 \mathrm{~h}$. The contents of extractives (NREL/TP-510-42619) were estimated gravimetrically after an $8 \mathrm{~h}$ soxhlet extraction with $80 \%$ ethanol in a Soxtec ${ }^{\mathrm{TM}} 8000$ extraction unit (FOSS, Tecator, Hillerød, Denmark). Soluble glucose polysaccharides (SGP) in extractives were measured as glucose released after acid posthydrolysis of the extractives fraction, with $\mathrm{H}_{2} \mathrm{SO}_{4}$ at a concentration of $4 \%\left(\mathrm{w} \mathrm{w}^{-1}\right)$ (Sigma-Aldrich) at $121{ }^{\circ} \mathrm{C}$ for $1 \mathrm{~h}$, taking into account the respective anhydro correction factor.

Glucan, xylan, arabinan and lignin content of extractive-free BSG samples were determined by analytical quantitative acid hydrolysis (NREL/TP-510-42618). Briefly, approximately $0.5 \mathrm{~g}$ of each dry BSG type were milled to a $<0.5 \mathrm{~mm}$ particle size and treated with $5 \mathrm{~mL}$ of $72 \%\left(\mathrm{w} \mathrm{w} \mathrm{w}^{-1}\right) \mathrm{H}_{2} \mathrm{SO}_{4}$ at $30^{\circ} \mathrm{C}$, for $1 \mathrm{~h}$, under periodic agitation. The reaction mixture was then diluted for reduction of $\mathrm{H}_{2} \mathrm{SO}_{4}$ concentration to $4 \%\left(\mathrm{w} \mathrm{w}^{-1}\right)$ and autoclaved for $1 \mathrm{~h}$ at $121^{\circ} \mathrm{C}$. Subsequently, the solids were filtered using a filtration crucible (pore size 3, Schott, Germany) and dried at $105^{\circ} \mathrm{C}$ for $24 \mathrm{~h}$ to remove all the moisture content or until constant weight was achieved. The acid insoluble residue recovered from filtration was gravimetrically measured and reported as Klason lignin. Monosaccharides contained in the hydrolysates were analyzed by HPLC, as described below, allowing the determination (after appropriate corrections for stoichiometry and sugar decomposition) of glucan, xylan and arabinan content of each BSG. Nitrogen content was estimated by the Kjeldahl method, according to the official method of analysis of Association of Official Analytical Chemists (AOAC 984.13.) [28]. Samples were prepared and measured using a Kjeltec ${ }^{\mathrm{TM}} 8400$ Analyzer (FOSS Tecator, Hoganos, Sweden). Protein content was calculated from nitrogen using a conversion factor of 6.25 .

\section{Autohydrolysis pretreatment}

Autohydrolysis treatments were performed in a stainless-steel reactor (Parr Instruments Company, Moline, Illinois, USA) of $2 \mathrm{~L}$ internal volume, heated by an external mantle, and a PID controller (model 4848) was used to control the temperature. The reactor was cooled with cold water circulating through an internal loop. The appropriate amount of BSG was blended with water, in the reactor, to achieve the desired solid loading ( 20 and $25 \%$ ) expressed as $g$ of raw material per $100 \mathrm{~cm}^{3}$ of water, taking into account the moisture content of the sample.

Autohydrolysis assays were carried out at $150 \mathrm{rpm}$ agitation, the reactor was heated until the target temperature $\left(150-170{ }^{\circ} \mathrm{C}\right)$, which was maintained for $5 \mathrm{~min}$, and then immediately cooled. When the treatment was complete, the solid residues were separated from the liquor by centrifugation $\left(10,000 \mathrm{~g}, 15 \mathrm{~min}, 7^{\circ} \mathrm{C}\right)$. The recovered solid was washed exhaustively with water for solid yield determination (SY, $\mathrm{g}$ solid recovered per $100 \mathrm{~g}$ raw material, oven dry basis) and assayed for chemical composition (glucan, xylan and arabinan), following the same methods described for raw material. The liquid phase was subjected to two different types of analyzes. A sample of the hydrolysate (autohydrolysis liquor) was filtered through $0.22 \mu \mathrm{m}$ nylon membranes and used for direct HPLC determination of glucose, xylose, acetic acid, hydroxymethylfurfural (HMF) and furfural. A second sample was submitted to quantitative acid posthydrolysis with $4 \%$ (w w $\left.{ }^{-1}\right) \mathrm{H}_{2} \mathrm{SO}_{4}$ $\left(121^{\circ} \mathrm{C}, 1 \mathrm{~h}\right)$ and analyzed by HPLC for oligosaccharides quantitation. The oligomer concentration was calculated from the increase in sugar monomers, before and after posthydrolysis. The individual effect of temperature and solid loadings on pretreatment efficiency were investigated using selected BSGs.

\section{Enzymatic saccharification of untreated and pretreated BSGs}

All enzyme hydrolysis reactions were carried out in an orbital shaker at $50{ }^{\circ} \mathrm{C}, 200 \mathrm{rpm}$ and $\mathrm{pH} 4.8$ (with $0.05 \mathrm{~N}$ sodium citrate buffer), in $100 \mathrm{~mL}$ Erlenmeyer flasks (working volume of 40 or $50 \mathrm{~mL}$ ) in duplicate. For these experiments, a commercial cellulase mixture, "Cellic CTec2" from Trichoderma reesei, (kindly provided by Novozymes, Bagsvaerd, Denmark), was used in an enzyme dosage of $15 \mathrm{FPU} \mathrm{g}^{-1}$ biomass. The Cellic CTec2 had a total cellulase activity of 120 FPU $\mathrm{mL}^{-1}$, which was measured according to the procedure described in [29]. Experiments were prepared by mixing the adequate amounts of substrate (untreated or treated BSG) with buffer and water, followed by sterilization by autoclave, at $121{ }^{\circ} \mathrm{C}$ for $15 \mathrm{~min}$ and cooling before adding the enzyme. The saccharification assays were monitored through periodical sample collections, and analyzed for glucose concentration via HPLC, except for the tests carried out at the highest solids loading, where sampling was only possible at the end of the saccharification.

The efficiency of all enzymatic saccharifications was verified via the achieved glucose yields $\left(\mathrm{Y}_{G}\right)$ calculated by the following equation:

$Y_{G}=\frac{G}{\frac{180}{162} \cdot G n \cdot B S G} \cdot 100$

where, $G$ is the concentration of glucose $\left(\mathrm{g} \mathrm{L}^{-1}\right)$ in enzymatic saccharification assays, $B S G$ is the concentration of dry brewer's spent grain or pretreated brewer's spent grain at $120 \mathrm{~h}$ of enzymatic saccharification assays, taking into account the polysaccharides solubilization for the correction of final volume $\left(\mathrm{g} \mathrm{L}^{-1}\right), \mathrm{Gn}$ is the glucan fraction in dry BSG or pretreated BSG $\left(\mathrm{g} \mathrm{g}^{-1}\right)$, and $180 / 162$ is the stoichiometric factor for glucan hydration upon hydrolysis. 
Table 1

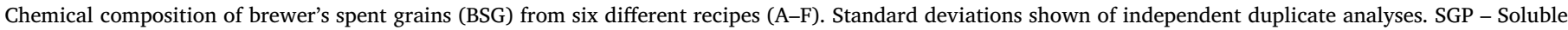
glucose polysaccharides.

\begin{tabular}{|c|c|c|c|c|c|c|c|}
\hline Components (g $100 \mathrm{~g}^{-1}$ of dry BSG) & BSG A & BSG B & BSG C & BSG D & BSG E & BSG F & Reported $^{\mathrm{a}}$ \\
\hline \multirow[t]{2}{*}{ Total glucan Of which SGP } & $26.6 \pm 0.7$ & $26.5 \pm 0.5$ & $28.6 \pm 2.3$ & $31.3 \pm 1.6$ & $32.1 \pm 1.9$ & $29.0 \pm 0.7$ & $16.8-26.0$ \\
\hline & $3.4 \pm 0.3$ & $2.2 \pm 0.3$ & $2.9 \pm 0.7$ & $2.2 \pm 0.7$ & $7.6 \pm 0.7$ & $2.9 \pm 0.7$ & \\
\hline Xylan & $11.5 \pm 0.2$ & $10.6 \pm 0.3$ & $9.1 \pm 0.2$ & $12.5 \pm 0.8$ & $7.0 \pm 0.5$ & $10.9 \pm 0.4$ & $13.6-20.6$ \\
\hline Arabinan & $5.8 \pm 0.3$ & $5.2 \pm 0.4$ & $4.42 \pm 0.04$ & $5.3 \pm 0.5$ & $2.6 \pm 0.1$ & $5.1 \pm 0.2$ & $5.6-9.0$ \\
\hline Total lignin & $11.0 \pm 0.3$ & $11.4 \pm 0.5$ & $14.5 \pm 0.8$ & $12.1 \pm 1.0$ & $8.9 \pm 0.6$ & $9.9 \pm 0.2$ & $11.9-27.8$ \\
\hline Klason lignin & $7.7 \pm 0.2$ & $8.8 \pm 0.3$ & $11.7 \pm 0.7$ & $9.1 \pm 0.8$ & $6.7 \pm 0.4$ & $7.0 \pm 0.2$ & \\
\hline Acid-soluble lignin & $3.3 \pm 0.2$ & $2.7 \pm 0.2$ & $2.89 \pm 0.08$ & $3.1 \pm 0.2$ & $2.3 \pm 0.1$ & $2.92 \pm 0.06$ & \\
\hline Proteins & $19.1 \pm 0.2$ & $19.9 \pm 0.5$ & $18.1 \pm 0.5$ & $20.2 \pm 0.1$ & $14.3 \pm 0.9$ & $17.2 \pm 0.9$ & $15.3-24.7$ \\
\hline Ashes & $2.87 \pm 0.05$ & $3.73 \pm 0.08$ & $2.89 \pm 0.05$ & $3.47 \pm 0.07$ & $1.93 \pm 0.04$ & $2.85 \pm 0.03$ & $1.1-4.6$ \\
\hline Extractives & $22.5 \pm 1.1$ & $19.6 \pm 0.7$ & $19.7 \pm 0.9$ & $12.9 \pm 0.4$ & $29.8 \pm 2.2$ & $21.7 \pm 0.5$ & $5.8-10.7$ \\
\hline
\end{tabular}

a Adapted from [2].

\section{Yeast strains and inoculum preparation}

The strains selected for bioethanol production were $S$. cerevisiae Belgian Abbey II strain 1762 (Wyeast Laboratories Inc.), designated in short as BLGII 1762, a high gravity brewing yeast, and S. cerevisiae PE2 , isolated from the Brazilian bioethanol industry with proven efficiency in high-gravity conditions [30-32]. For inoculum preparation, cells were pitched in $500 \mathrm{~mL}$ Erlenmeyer flasks, filled with $200 \mathrm{~mL}$ of YPD medium and grown at $30^{\circ} \mathrm{C}, 200 \mathrm{rpm}$ for $24 \mathrm{~h}$. The cell suspension was then aseptically collected by centrifugation for $10 \mathrm{~min}$ at $10,000 \mathrm{~g}$ and $4{ }^{\circ} \mathrm{C}$ and resuspended in $0.9 \%\left(\mathrm{w} \mathrm{v}^{-1}\right) \mathrm{NaCl}$ solution, in order to reach a final concentration of $200 \mathrm{mg}$ of fresh yeast per $\mathrm{mL}$. The fermentation assays were inoculated at a cellular concentration of $7 \mathrm{mg}$ of fresh yeast per $\mathrm{mL}$.

\section{Hybrid saccharification and fermentation of autohydrolyzed BSG}

Whole slurries from autohydrolysis pretreatment of BSG samples were employed as substrate for ethanol production by Hybrid Saccharification and Fermentation (HSF), in order to evaluate the fermentation performance of the two yeast strains. HSF assays were carried out in duplicate. The whole slurries were sterilized by autoclave $\left(121^{\circ} \mathrm{C}, 15 \mathrm{~min}\right)$ with $\mathrm{pH}$ adjusted to 4.8 , using $0.05 \mathrm{~N}$ sodium citrate buffer. All the experiments were conducted in $100 \mathrm{~mL}$ Erlenmeyer flasks (fixed volume of $50 \mathrm{~mL}$ ). The enzymatic hydrolysis stage was conducted using the Cellic CTec 2 enzyme cocktail at $50{ }^{\circ} \mathrm{C}, 200 \mathrm{rpm}$, with an enzyme dosage of 15 FPU per gram of dry matter. After approximately $120 \mathrm{~h}$ of saccharification, the temperature and agitation were decreased and maintained at $30^{\circ} \mathrm{C}$ and $150 \mathrm{rpm}$, respectively, and the yeast was added to start the fermentation stage. To achieve anaerobic conditions, flasks were fitted with perforated rubber stoppers enclosing glycerol-locks, which allow $\mathrm{CO}_{2}$ release and avoid $\mathrm{O}_{2}$ entry. In this case, fermentation progression was tracked by periodic weight loss measurement, equivalent to $\mathrm{CO}_{2}$ production in the fermentation and directly associated with conversion of sugars to ethanol and $\mathrm{CO}_{2}$. Upon completion of the fermentation, samples were taken for HPLC analysis for glucose, xylose and ethanol quantitation. The results were expressed in terms of ethanol concentration $\left(\mathrm{g} \mathrm{L}^{-1}\right)$ and ethanol yield ( $Y_{E t O H} \mathrm{~g}$ of ethanol per $100 \mathrm{~g}$ of ethanol potential), using the following equation:

$Y_{E t O H}=\frac{C_{E t O H}}{0.511 \cdot \frac{180}{162} \cdot G n \cdot B S G} \cdot 100$

where $C_{E t O H}$ is the ethanol concentration at the end of the HSF assays $\left(\mathrm{g} \mathrm{L}^{-1}\right), 0.511$ is the stoichiometric factor for glucose conversion into ethanol, 180/162 is the stoichiometric factor for glucan hydration upon hydrolysis, $G n$ is the glucan fraction in dry BSG or pretreated BSG $\left(\mathrm{g} \mathrm{g}^{-1}\right)$, BSG is the concentration of brewer's spent grain or pretreated brewer's spent grain in the HSF assays taking into account the polysaccharides solubilization for the correction of final volume of fermentation $\left(\mathrm{g} \mathrm{L}^{-1}\right)$.

\section{Analytical methods}

Samples collected from analytical composition of raw material, pretreatment solid fraction, autohydrolysis liquor, saccharification assays and fermentation runs were analyzed for glucose, xylose, arabinose, acetic acid, ethanol, furfural and HMF concentration by high performance liquid chromatography (HPLC) using an Aminex HPX-87H column (Bio-Rad, Hercules, CA, USA). Chromatography was carried out at $60{ }^{\circ} \mathrm{C}$, with a $5 \mathrm{mM} \mathrm{H} \mathrm{H}_{2} \mathrm{SO}_{4}$ mobile phase and flow rate of $0.6 \mathrm{~mL} \mathrm{~min}^{-1}$. The peaks corresponding to sugars, alcohol and acetic acid were detected using a Knauer-IR refractive index detector, while furfural and HMF were detected using a Knauer-UV detector set at $210 \mathrm{~nm}$. Proper pure standards were used for quantitation.

All experiments (pretreatments, enzymatic hydrolysis reactions, and fermentations) were conducted in duplicate.

\section{Results and discussion}

\section{Compositional analysis of BSG}

Craft beer production resorts to a wide variety of recipes, which by the use of different malts, cereal proportions, mashing conditions, hops and yeast, lead to the production of diverse beer styles. Thus, considering variations in malts and mashing conditions, the spent grains wastes generated are also expected to be heterogeneous in composition. In order to assess and evaluate the potential of craft brewer's spent grains, six lots of BSG obtained from different beer recipes were chemically characterized, with the results presented in Table 1 .

BSG is a lignocellulosic waste, mainly comprising fibers (cellulose and hemicellulose), lignin and protein. Cellulose is a crystalline, linear polymer of glucose and hemicellulose is a branched heterogeneous polysaccharide, composed of pentoses (such as xylose and arabinose) and hexoses (such as glucose, mannose and galactose), which can be substituted with uronic acids, acetyl groups and esterified phenolic acids.

Glucan was the main fraction found in the majority of the analyzed

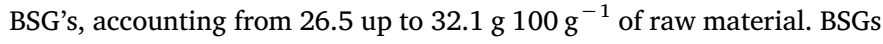
$\mathrm{D}$ and $\mathrm{E}$ showed the highest glucan content. The percentage of extractives varied in the analyzed BSGs between 12.9 to $29.8{\mathrm{~g} 100 \mathrm{~g}^{-1}}^{-1}$ which can comprise waxes, fats, gums, starches, resins, tannins, essential oils and various other cytoplasmic constituents [33]. BSG E had the higher amount of extractives and D the lowest. After hydrolysis of extractives, the analysis of sugars revealed a significant percentage of extractable/soluble glucose polysaccharides (SGP), ranging from 2.2 to 3.4 per $100 \mathrm{~g}$ of raw material for all BSGs, except for BSG E which showed up to $7.6 \mathrm{~g}$ of SGP per $100 \mathrm{~g}$ of raw material. Such extractable sugars are expected in the extractive fraction, deriving from non- 
converted starch in BSG [33,34]. Taking into account that craft production resorts to process configurations and methodologies that lead to lower mashing efficiencies, the grain generated by these processes will consequently be "less spent", possessing higher non-converted glucan content. Indeed, in comparison, total glucan content (insoluble and soluble) of the analyzed BSG exceeded the common values reported in

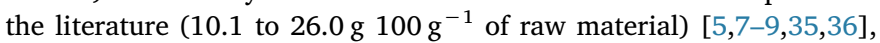
positioning craft BSG as a favorable raw material for ethanol production when compared to conventional industrial BSG, due to its higher glucose content.

The second most prominent polysaccharide in the BSG was xylan,

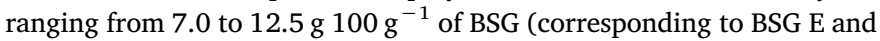
$\mathrm{D}$, respectively). Xylose is a sugar constituent of the hemicellulosic fraction and typically its content tends to be close to or even higher than glucan in BSG waste $[4,37]$. However, due to the higher glucan content found for BSG here, along with the high content in extractives, xylan content was lower when compared to that reported in the lit-

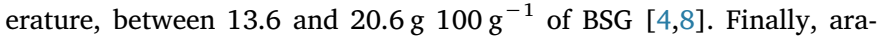
binan was the polysaccharide present at lower levels in BSG, ranging

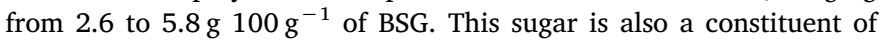
hemicellulose and also appeared in lower content when compared to the literature $[4,38]$. Arabinan content was similar between all BSGs with the exception of BSG E where it was lower.

Alongside glucan and extractives, protein was the third major fraction of BSG, representing between 14.3 and $20.2 \%$ of the raw material, consistent with the values reported in literature (between 14.2 and 31\%) [5-9,35]. BSG also presented a low percentage of lignin in its

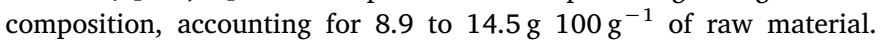
Ashes were the fraction present in minor proportion in the analyzed BSG, ranging from 1.93 to $3.73 \mathrm{~g}$ per $100 \mathrm{~g}$ of BSG. Overall BSG composition can be positively compared with that found in previous studies, standing out with a higher glucan content, a favorable feature when envisaging ethanol production. BSG composition was highly heterogeneous within the analyzed samples, demonstrating that different beer productions affect the characteristics of the spent grain produced. Taking into account the results of the BSG characterization, two were chosen for the pretreatments assays, namely BSG E due to its high glucan and SGP content and BSG D due to its high glucan but low SGP content.

\section{Evaluation of autohydrolysis treatment}

In order to minimize glucose degradation, mild conditions of autohydrolysis pretreatment were selected based on literature reports $[17,39]$. BSG E was submitted to autohydrolysis pretreatment at 150, 160 and $170{ }^{\circ} \mathrm{C}$ for $5 \mathrm{~min}$, using a fixed solid loading of $20 \%\left(\mathrm{w} \mathrm{v}^{-1}\right)$. The effect of temperature on BSG fractionation was evaluated by chemical characterization of solid and liquid phases. Increase in pretreatment temperatures led to differences in fractionation of BSG, mainly in glucan, glucooligosaccharides and glucose. Most of the potential glucose was found in the pretreatment liquor (Fig. 1), in the form of glucooligosaccharides, which is typical of autohydrolysis processes at mild temperatures. Starch has anhydroglucose units, linked by $\alpha-1,4$-glicosidic bounds, which are more easily hydrolyzed in conditions milder than those needed for cellulose and hemicellulose [40]. Therefore, a representative fraction of the glucan initially present in the raw material was easily extracted to the liquid fraction ( $>50 \%$ ). This has also been observed, but at lower expression, in previous studies, where glucooligosaccharide extraction was approximately 3-fold lower with higher autohydrolysis temperature [41]. Moreover, glucan recovery observed here was similar to that obtained by others using acid hydrolysis [42].

With respect to the solid phase, the glucan content of pretreated BSG at different temperatures varied from 24.3 to $27.7 \mathrm{~g}$ of glucan $100 \mathrm{~g}^{-1}$ of pretreated BSG E. In the liquid phase, concentrations of glucooligosaccharides were $37.3,36.6$ and $32.5 \mathrm{~g} \mathrm{~L}^{-1}$ for treatments at

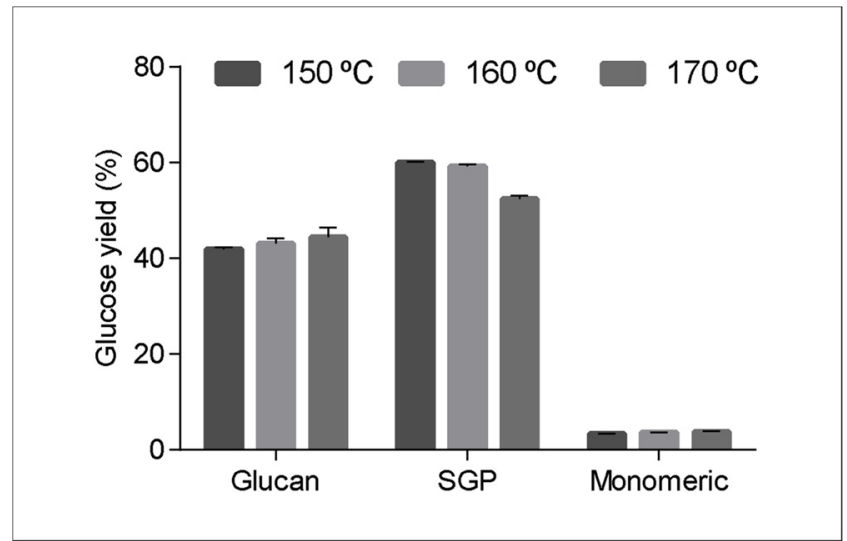

Fig. 1. Effect of autohydrolysis temperature on the recovery of glucan from BSG $\mathrm{E}$ in the fractions of cellulose/hemicellulose (glucan), soluble glucose polysaccharides deriving from starch (SGP) and free glucose monomers (monomeric). Glucose yields are expressed in reference to total glucan initially available in the raw material.

150,160 and $170^{\circ} \mathrm{C}$, respectively. Autohydrolysis liquor of pretreated BSG at $170^{\circ} \mathrm{C}$ showed a significantly lower glucooligosaccharide content compared with the liquors pretreated at $150^{\circ} \mathrm{C}$ and $160^{\circ} \mathrm{C}$. Therefore, an increase in autohydrolysis temperature from $160^{\circ} \mathrm{C}$ to $170{ }^{\circ} \mathrm{C}$ led to a decrease in glucan recovery in the liquor, which can be related to glucose degradation. Monomeric glucose was found at residual levels (between $2.33-2.68 \mathrm{~g} \mathrm{~L}^{-1}$ ) in the autohydrolysis liquor and no statistically significant differences were found between any of the tested temperatures for a $95 \%$ confidence interval.

To further assess pretreatment efficiency, enzymatic hydrolysis was evaluated in order to determine saccharification susceptibility. Glucose yield of BSG pretreated at different temperatures is shown in Fig. 2. About $70 \%$ of the glucan present in the solids pretreated at $150{ }^{\circ} \mathrm{C}$ and $160{ }^{\circ} \mathrm{C}$ was hydrolyzed, whereas the solid pretreated at $170{ }^{\circ} \mathrm{C}$ showed only about $55 \%$ saccharification of the available glucan.

An increase of temperature up to $170{ }^{\circ} \mathrm{C}$ did not improve enzymatic saccharification of the remaining glucan in pretreated BSG. This could be due to the presence of more lignin related with an increase of the treatment severity factor. Others reported that a higher severity factor did not lead directly to a better enzymatic hydrolysis, demonstrating that for higher severity factors there is higher lignin liberation [43] which acts as inhibitor of enzymatic hydrolysis [44]. In fact, taking into account the solid phase composition, the lignin content in the solid resulting from BSG pretreatment at $170{ }^{\circ} \mathrm{C}$ was significantly higher

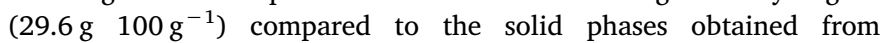

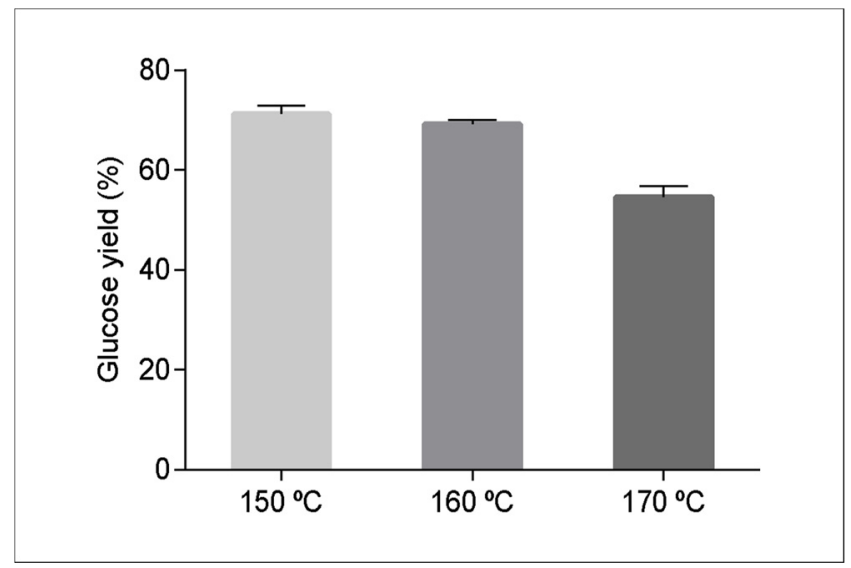

Fig. 2. Influence of autohydrolysis temperature on the glucose yield (\%) of enzymatic saccharification of BSG E. 


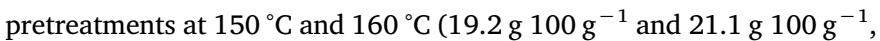
respectively), which could lead to inhibition of enzymatic saccharification and consequently the lower efficiency observed. Therefore, $160^{\circ} \mathrm{C}$ was selected as the optimum autohydrolysis condition which led to a higher glucose recovery.

\section{Effect of solid loading on autohydrolysis pretreatment}

Few studies have focused pretreatment at high-load solids, with most of the pretreatment strategies being performed at $5-10 \%\left(\mathrm{w} \mathrm{v}^{-1}\right)$ of solids. The use of solid loadings greater than $15 \%\left(\mathrm{w} \mathrm{v}^{-1}\right)$ has great potential for improving process economics of lignocellulose conversion by increasing sugar and ethanol yields while decreasing production and capital costs. Highsolid loadings however offer many challenges, such as high concentrations of inhibitors and mass transfer limitations which negatively affect process efficiency [45].

On the basis of the previous results, autohydrolysis pretreatment at high solid loadings was applied to BSG D and BSG E. Taking this into account, two solid loadings were tested: BSG D was pretreated at $20 \%$ and $25 \%\left(\mathrm{w} \mathrm{v}^{-1}\right)$, while BSG E was pretreated at 25\% $\left(\mathrm{w} \mathrm{v}^{-1}\right)$. Compositions of the fractions resulting from the different pretreatments are presented in Table 2.

For the solid phase of the pretreated BSG, glucan was the fraction found in the highest concentration, in agreement with the previous pretreatment results obtained at lower solid loadings. A high amount of glucan originally present in the raw material was extracted to the liquid phase during pretreatment, with only $33 \%$ of the original glucan remaining in the pretreated solid for BSG E. For BSG D, the degree of glucan solubilization was lower (approximately 50\%), which is related to the SGP content previously discussed. Xylan was the second predominant fraction in all pre-treated BSG solids, followed by lignin and arabinan at low percentage. Nevertheless, $1823 \%$ of the xylan was solubilized in the liquid phase as xylooligosaccharides, which is in good agreement with previously reported studies under similar pretreatment temperature and time [4].

The liquid phase of the pretreated BSG presented a high concentration of glucooligosaccharides, followed by xylooligosaccharides. Thus, a high percentage of glucan initially present in the raw material was solubilized into the autohydrolysis liquor, leading to a high concentration of glucose being immediately accessible for saccharification and fermentation. For BSG D, no statistically significant differences were observed for glucan and xylan composition in the pretreated solid between the pretreatments at 20 and $25 \%$ solid loadings. In contrast, increasing solid loading lead to an increase on glucooligosaccharide concentration in the liquid phase, a direct effect of increasing raw material concentration. Acetic acid was found in all the pretreated conditions with a concentration range from 0.6 to $1.3 \mathrm{~g} \mathrm{~L}^{-1}$. The presence of acetic acid in the liquid phase is not unexpected, considering that it is the process catalyst, a consequence of hemicellulose's acetyl group hydrolysis. HMF and furfural were also quantified at low concentrations, deriving from hexose and pentose degradation. HMF increased significantly with increasing solid loading for BSG D pretreatments, going from $0.064 \mathrm{~g} \mathrm{~L}^{-1}$ for $20 \%\left(\mathrm{w} \mathrm{v}^{-1}\right.$ ) to $1.5 \mathrm{~g} \mathrm{~L}^{-1}$ for $25 \%$ (w $\mathrm{v}^{-1}$ ), implying higher hexose degradation with the increased pretreatment solid loading. However, BSG E pretreated at $25 \%\left(\mathrm{w} \mathrm{v}^{-1}\right)$ showed an intermediate HMF concentration of $0.21 \mathrm{~g} \mathrm{~L}^{-1}$. Acetic acid along with HMF and furfural, can act as an inhibitors of yeast performance during alcoholic fermentations [46], but the concentrations were low when compared to those elsewhere using other pretreatments $[4,17]$. When compared to BSG D pretreated with the same conditions, pretreated BSG E solid showed similar glucan and xylan content. The autohydrolysis liquor of pretreated BSG E showed significantly higher glucooligosaccharide concentration than that of pretreated BSG D. This is related to the higher glucan concentration in the form of SGP, which was more immediately extracted to the liquor as an effect of the temperature.

\section{Enzymatic saccharification of untreated and pretreated BSG at different solid loadings}

In order to evaluate the effect of pretreatment on overall process yield, saccharification of whole slurry of pretreated BSG was compared with untreated BSG, at low and high solid loadings. Glucose yields $\left(Y_{G}\right)$ were determined at $120 \mathrm{~h}$ of saccharification, presented in Fig. 3. For the untreated BSG, saccharification yield decreased with the increase of solid loading. In fact, high solid loading may hinder the enzymatic saccharification as result of poor efficiency of mass transfer [45,47].

An increase of solid loadings up to $20 \%\left(\mathrm{w} \mathrm{v}^{-1}\right)$ allowed an increase in glucose concentration, despite the losses in saccharification efficiency. However, when increasing solid loading from 20 to $25 \%$ (w $\mathrm{v}^{-1}$ ), decrease in saccharification yield was so high that there was no increase in glucose concentration. This barrier was overcome with autohydrolysis pretreatment, which improved the glucose yield of saccharification compared with untreated raw material, enabling the operation of up to 20 and $25 \%\left(\mathrm{w} \mathrm{v}^{-1}\right)$ of solids. As seen, $60 \mathrm{~g} \mathrm{~L}^{-1}$ of glucose (corresponding to $70 \%$ of glucose yield) was obtained at $25 \%$ $\left(\mathrm{w} \mathrm{v}^{-1}\right)$ of whole slurry from pretreated BSG. For $20 \%\left(\mathrm{w} \mathrm{v}^{-1}\right)$, pretreatment of BSG allowed a $28 \%$ higher saccharification yield than the untreated sample and for $25 \%\left(\mathrm{w} \mathrm{v}^{-1}\right)$ the increase in yield was $23 \%$. These results represent an improvement over those recently reported, where $40 \mathrm{~g} \mathrm{~L}^{-1}$ glucose concentration was achieved with a glucose yield of $40 \%$ after $72 \mathrm{~h}$ of enzyme saccharification of pretreated BSG

Table 2

Composition of hydrothermally pretreated brewer's spent grains D and E at different solid loadings (Solid Liquid Ratio). Data were expressed in $\mathrm{g} 100 \mathrm{~g}{ }^{-1}$ of BSG or pretreated BSG in oven-dry basis \pm standard deviation based on duplicate independent replicate determinations.

\begin{tabular}{|c|c|c|c|}
\hline & \multirow{2}{*}{$\begin{array}{l}\text { SLR } 20 \%\left(\mathrm{w} \mathrm{v}^{-1}\right) \\
\text { BSG D }\end{array}$} & \multicolumn{2}{|l|}{ SLR $25 \%\left(\mathrm{w} \mathrm{v}^{-1}\right)$} \\
\hline & & BSG D & BSG E \\
\hline Solid yield ( $\mathrm{g}$ of pretreated BSG $100 \mathrm{~g}^{-1}$ of BSG) & $72.8 \pm 5.8$ & $71.7 \pm 6.6$ & $48.6 \pm 5.6$ \\
\hline \multicolumn{4}{|l|}{ a. Chemical composition of solid phase ( $\mathrm{g}$ of component $100 \mathrm{~g}^{-1}$ of hydrothermally pretreated raw material) } \\
\hline Glucan & $21.5 \pm 1.6$ & $22.4 \pm 1.6$ & $21.8 \pm 1.5$ \\
\hline Xylan & $14.3 \pm 1.2$ & $13.4 \pm 1.8$ & $11.3 \pm 1.8$ \\
\hline Arabinan & $4.1 \pm 0.1$ & $3.9 \pm 0.3$ & $4.4 \pm 0.4$ \\
\hline Klason lignin & $10.2 \pm 1.3$ & $16.3 \pm 1.2$ & $26.5 \pm 2.3$ \\
\hline \multicolumn{4}{|l|}{ b. Chemical composition of liquid phase or autohydrolysis liquor $\left(\mathrm{g} \mathrm{L}^{-1}\right)$} \\
\hline Glucooligosaccharides & $25.2 \pm 1.6$ & $34.2 \pm 1.5$ & $51.6 \pm 2.3$ \\
\hline Xylooligosaccharides & $5.37 \pm 0.06$ & $6.03 \pm 0.9$ & $3.9 \pm 04$ \\
\hline Glucose & $0.41 \pm 0.07$ & $0.46 \pm 0.02$ & $3.2 \pm 0.3$ \\
\hline Xylose & $0.36 \pm 0.02$ & $0.32 \pm 0.01$ & $0.51 \pm 0.03$ \\
\hline Acetic acid & $0.6 \pm 0.2$ & $0.86 \pm 0.04$ & $1.3 \pm 0.1$ \\
\hline HMF & $0.064 \pm 0.007$ & $1.5 \pm 0.5$ & $0.21 \pm 0.07$ \\
\hline Furfural & $0.13 \pm 0.03$ & $0.127 \pm 0.004$ & $0.255 \pm 0.009$ \\
\hline
\end{tabular}


a)

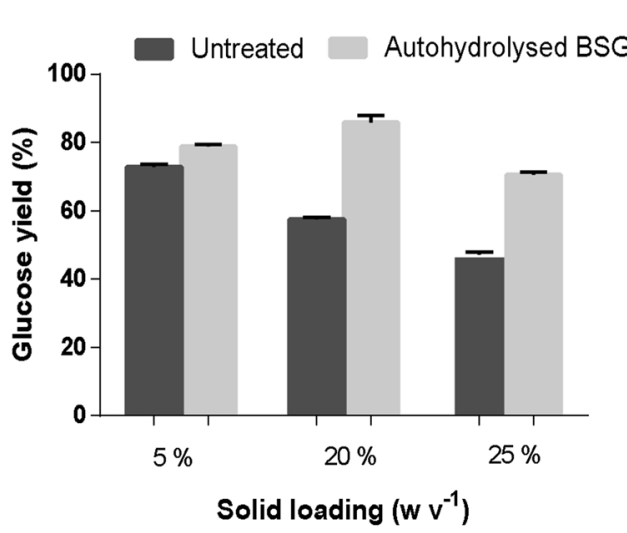

b)

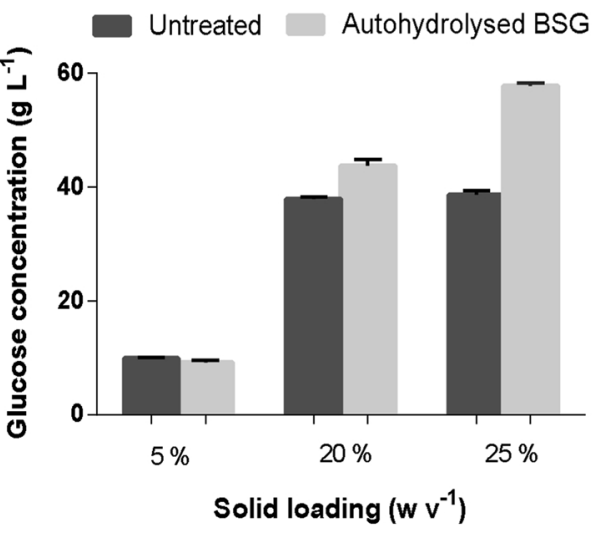

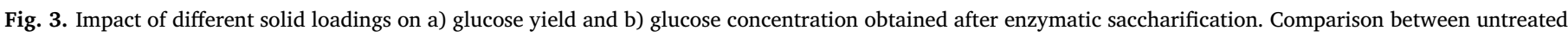
and whole slurry of BSG D pretreated at $160{ }^{\circ} \mathrm{C}$.

( $1 \% \mathrm{HCl}, 121{ }^{\circ} \mathrm{C}, 30 \mathrm{~min}$ pretreatment, $25 \% \mathrm{w} \mathrm{v}^{-1}$ solids loading) [21]. Increasing solid loading from 20 to $25 \%\left(\mathrm{w} \mathrm{v}^{-1}\right)$ also led to a lower efficiency in enzymatic saccharification of the pretreated BSG, consistent with that observed for untreated BSG. However, in contrast to untreated BSG, the increase of solid loading from 20 to $25 \%$ combined with pretreatment of BSG allowed a significant increase in glucose concentration. As a novel approach using high solid loadings for BSG pretreatment, these results indicate a great advantage in the development of second generation bioethanol, considering the possibility of obtaining the high sugar concentration needed to improve ethanol concentrations, thus reducing distillation costs.

Hybrid saccharification and fermentation of BSG whole slurry for ethanol production

After evaluation of the effect of pretreatment conditions on the fractionation of BSG and susceptibility to enzymatic hydrolysis, whole slurries from pretreatment of BSG D and E were subjected to Hybrid Saccharification and Fermentation (HSF) by two different yeast strains, a brewer's yeast and a 1G (first generation) bioethanol industrial yeast previously screened and selected for $2 \mathrm{G}$ (second generation) bioethanol production with proven efficiency in hydrolysates from different raw materials [48-50]. $\mathrm{CO}_{2}$ production from the fermentation stage is presented in Fig. 4. As seen, fermentation of pretreated whole slurry of BSG E showed a higher $\mathrm{CO}_{2}$ production, which is consistent with the higher ethanol production observed, presented in Table 3 . The highest

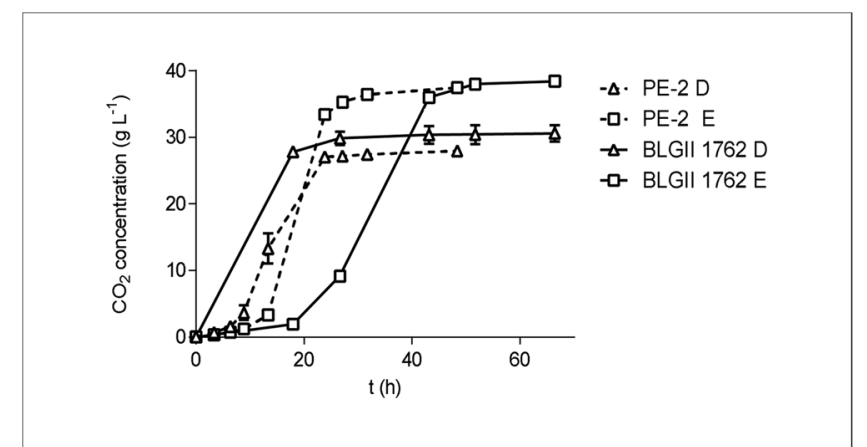

Fig. 4. Profiles depicting $\mathrm{CO}_{2}$ production along time (t) for hybrid saccharification and fermentation of whole slurries of BSG D and E pretreated at $160{ }^{\circ} \mathrm{C}$ at a solid loading of $25 \% \mathrm{w} \mathrm{v}^{-1}$ and fermented with yeast from $1 \mathrm{G}$ bioethanol industry, PE-2, or with yeast from brewery industry, BLGII 1762. ethanol concentration was obtained for HSF of BSG E with BLGII 1762 yeast, attaining $42.27 \mathrm{~g} \mathrm{~L}^{-1}$, followed by PE-2 yeast with $40.3 \mathrm{~g} \mathrm{~L}^{-1}$. Such concentrations are now feasible to envisage for a second generation bioethanol process from BSG [19]. BSG D led to lower ethanol concentrations with $32.2 \mathrm{~g} \mathrm{~L}^{-1}$ when fermented with BLGII 1762 yeast and $28.7 \mathrm{~g} \mathrm{~L}^{-1}$ for PE-2 fermentation. High yields were obtained for the overall process using whole slurry $\mathrm{E}$, with values between $82.0 \%$ and $94 \%$, which indicate a high process performance considering the multiple steps performed. BSG D on the other hand led to lower ethanol yields, between $65.5 \%$ and $73 \%$, which was related to the lower accessibility of the glucan in the raw material. In other reports, the highest reported ethanol yield was $81 \%$, for BSG pretreated with $5 \%$ $\mathrm{NaOH}$ and $25 \%\left(\mathrm{w} \mathrm{v}^{-1}\right)$ solids loading, representing a final ethanol titer of $17.9 \mathrm{~g} \mathrm{~L}^{-1}$ [10]. More recently, using harsher autohydrolysis conditions $\left(200^{\circ} \mathrm{C}, 10 \mathrm{~min}\right)$, only $22 \mathrm{~g} \mathrm{~L}^{-1}$ of ethanol were achieved, equivalent to about $75 \%$ of the theoretical yield [17]. Even envisaging a more realistic scenario, a mixture of all BSGs characterized would

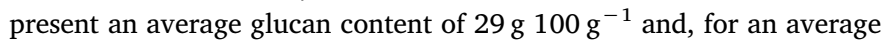
ethanol yield of $Y_{E t O H} \approx 79.75 \%$, final ethanol production would be $32.83 \mathrm{~g} \mathrm{~L}^{-1}$, or $4.2 \%$ by volume, which still surpasses the values reported in the literature and the threshold of $4 \%$ discussed previously for distillation economic feasibility. The ethanol titer and yield obtained in this study are the best reported so far for the bioconversion of BSG to ethanol. Moreover, this is the first study (as far as we are aware) to combine high ethanol concentration with high yield using BSG as feedstock.

\section{Conclusions}

Evaluation of 6 BSGs from a craft brewery demonstrated the difference in chemical composition and the higher potential of this renewable biomass as a source of glucose when compared to standard industrial BSG. Mild pretreatment conditions were more favorable for solubilizing glucose from BSG. Autohydrolysis enabled the enzymatic saccharification at high solid loadings, permitting glucose concentrations higher than $60 \mathrm{~g} \mathrm{~L}^{-1}$ without compromising efficiency. Through the combination of high solid loadings with the use of the whole slurry of pretreated BSG, ethanol concentrations of $40 \mathrm{~g} \mathrm{~L}^{-1}$ were obtained by HSF, paving the way for the economic feasibility of BSG-to-bioethanol conversion and/or derived processes. 
Table 3

Final glucose concentration $\left(\mathrm{G}_{\mathrm{tf}}\right)$, ethanol concentration $\left(\mathrm{C}_{\mathrm{EtOH}}\right)$ and ethanol yield $\left(\mathrm{Y}_{\mathrm{EtOH}}\right)$ of HSF of BSG D and E whole slurries with different yeast. Standard deviations were based on duplicate independent biological replicate determinations.

\begin{tabular}{|c|c|c|c|c|}
\hline Yeast & Condition & $\mathrm{Gt}_{f}\left(\mathrm{~g} \mathrm{~L}^{-1}\right)$ & $\mathrm{C}_{E t O H}\left(\mathrm{~g} \mathrm{~L}^{-1}\right)$ & $\mathrm{Y}_{\mathrm{EtOH}}(\%)$ \\
\hline \multirow[t]{2}{*}{ BLGII 1762} & Whole slurry D 25\% & $0.27 \pm 0.02$ & $32.2 \pm 0.6$ & $73 \pm 1$ \\
\hline & Whole slurry E $25 \%$ & $0.23 \pm 0.04$ & $42.27 \pm 0.03$ & $94 \pm 0.6$ \\
\hline \multirow[t]{2}{*}{ PE-2 } & Whole slurry D $25 \%$ & $0.081 \pm 0.001$ & $28.7 \pm 0.6$ & $59.5 \pm 1.2$ \\
\hline & Whole slurry E $25 \%$ & $0.261 \pm 0.006$ & $40.3 \pm 0.4$ & $82.0 \pm 2.0$ \\
\hline
\end{tabular}

\section{Acknowledgments}

This study was supported by the Portuguese Foundation for Science and Technology (FCT) under the scope of the strategic funding of UID/ BIO/04469/2019 unit and COMPETE 2020 (POCI-01-0145-FEDER006684), BioTecNorte operation (NORTE-01-0145-FEDER-000004) funded by European Regional Development Fund under the scope of Norte2020 - Programa Operacional Regional do Norte and MultiBiorefinery project (POCI-01-0145-FEDER-016403). Furthermore, authors acknowledge Fermentum-Engenharia das Fermentações Lda., for providing raw material for this work.

\section{References}

[1] Djukić-Vuković A, Mladenović D, Radosavljević M, Kocić-Tanackov S, Pejin J, Mojović L. Wastes from bioethanol and beer productions as substrates for $\mathrm{L}(+)$ lactic acid production-a comparative study. Waste Manag 2016;48:478-82.

[2] Mussatto SI. Brewer's spent grain: a valuable feedstock for industrial applications. J Sci Food Agric 2014;94:1264-75.

[3] Jay AJ, Parker ML, Faulks R, Husband F, Wilde P, Smith AC, et al. A systematic micro-dissection of brewers' spent grain. J Cereal Sci 2008;47:357-64.

[4] Carvalheiro F, Esteves MP, Parajó JC, Pereira H, Gırio FM. Production of oligosaccharides by autohydrolysis of brewery's spent grain. Bioresour Technol 2004;91:93-100.

[5] Waters DM, Jacob F, Titze J, Arendt EK, Zannini E. Fibre, protein and mineral fortification of wheat bread through milled and fermented brewer's spent grain enrichment. Eur Food Res Technol 2012;235:767-78.

[6] Santos M, Jiménez JJ, Bartolomé B, Gómez-Cordovés C, Del Nozal MJ. Variability of brewer's spent grain within a brewery. Food Chem 2003;80:17-21.

[7] Kanauchi O, Mitsuyama K, Araki Y. Development of a functional germinated barley foodstuff from brewer's spent grain for the treatment of ulcerative colitis. J Am Soc Brew Chem 2001;59:59-62.

[8] Mussatto SI, Roberto IC. Chemical characterization and liberation of pentose sugars from brewer's spent grain. J Chem Technol Biotechnol 2006;81:268-74.

[9] Xiros C, Topakas E, Katapodis P, Christakopoulos P. Hydrolysis and fermentation of brewer's spent grain by Neurospora crassa. Bioresour Technol 2008;99:5427-35.

[10] Wilkinson S, Smart KA, Cook DJ. Optimisation of alkaline reagent based chemical pre-treatment of brewers spent grains for bioethanol production. Ind Crops Prod 2014:62:219-27.

[11] White JS, Yohannan BK, Walker GM. Bioconversion of brewer's spent grains to bioethanol. FEMS Yeast Res 2008;8:1175-84.

[12] Xiros C, Christakopoulos P. Enhanced ethanol production from brewer's spent grain by a Fusarium oxysporum consolidated system. Biotechnol Biofuels 2009;2:4.

[13] Wilkinson S, Smart KA, Cook DJ. A comparison of dilute acid-and alkali-catalyzed hydrothermal pretreatments for bioethanol production from brewers' spent grains. J Am Soc Brew Chem 2014:72:143-53.

[14] Xiros C, Topakas E, Katapodis P, Christakopoulos P. Evaluation of Fusarium oxysporum as an enzyme factory for the hydrolysis of brewer's spent grain with improved biodegradability for ethanol production. Ind Crops Prod 2008;28:213-24.

[15] Kemppainen K, Rommi K, Holopainen U. Steam explosion of brewer's spent grain improves enzymatic digestibility of carbohydrates and affects solubility and stability of proteins. Appl Biochem Biotechnol 2016;180:94-108.

[16] Heredia-Olea E, Pérez-Carrillo E, Serna-Saldívar SO. Effect of extrusion conditions and hydrolysis with fiber-degrading enzymes on the production of C5 and C6 sugars from brewers' spent grain for bioethanol production. Biofuel Res J 2015;2:203-8.

[17] Wilkinson S, Smart KA, Cook DJ. Optimising the (microwave) hydrothermal pretreatment of brewers spent grains for bioethanol production. J Fuels 2015;2015:1-13.

[18] Koppram R, Tomás-Pejó E, Xiros C, Olsson L. Lignocellulosic ethanol production at high-gravity: challenges and perspectives. Trends Biotechnol 2014:32:46-53.

[19] Zacchi G, Axelsson A. Economic evaluation of preconcentration in production of ethanol from dilute sugar solutions. Biotechnol Bioeng 1989;34:223-33.

[20] Wingren A, Galbe M, Zacchi G. Techno-economic evaluation of producing ethanol from softwood: comparison of SSF and SHF and identification of bottlenecks. Biotechnol Prog 2003;19:1109-17.

[21] Wilkinson S, Smart KA, James S, Cook DJ. Maximising high solid loading enzymatic saccharification yield from acid-catalysed hydrothermally-pretreated brewers spent grain. Biofuel Res J 2016;3:417-29.
[22] Moreno AD, Ibarra D, Ballesteros I, Fernández JL, Ballesteros M. Ethanol from laccase-detoxified lignocellulose by the thermotolerant yeast Kluyveromyces marxianus-effects of steam pretreatment conditions, process configurations and substrate loadings. Biochem Eng J 2013;79:94-103.

[23] Cassells B, Karhumaa K, Sànchez i Nogué V, Lidén G. Hybrid SSF/SHF processing of $\mathrm{SO}_{2}$ pretreated wheat straw-tuning co-fermentation by yeast inoculum size and hydrolysis time. Appl Biochem Biotechnol 2017;181:536-47.

[24] Palmqvist B, Lidén G. Combining the effects of process design and pH for improved xylose conversion in high solid ethanol production from Arundo donax. AMB Express 2014;4:41.

[25] Tengborg C, Galbe M, Zacchi G. Reduced inhibition of enzymatic hydrolysis of steam-pretreated softwood. Enzyme Microb Technol 2001;28:835-44.

[26] Xiros C, Olsson L. Comparison of strategies to overcome the inhibitory effects in high-gravity fermentation of lignocellulosic hydrolysates. Biomass Bioenergy 2014;65:79-90

[27] National Renewable Energy Laboratory (NREL). Laboratory analytical procedures. 2017 [Accessed 1 December 2017]. https://www.nrel.gov/bioenergy/laboratory-\% 0Aanalytical-procedures.html.

[28] Protein (crude) determination in animal feed: copper catalyst Kjeldahl method (984.13). In: Association of Official Analytical Chemistseditor. Official methods of analysis. $12^{\text {th }}$ ed.1984. p. 1141. Washington DC.

[29] Ghose TK. Measurement of cellulase activities. Pure Appl Chem 1987;59:257-68.

[30] Pereira FB, Guimarães PMR, Teixeira JA, Domingues L. Selection of Saccharomyces cerevisiae strains for efficient very high gravity bio-ethanol fermentation processes. Biotechnol Lett 2010;32:1655-61.

[31] Pereira FB, Guimarães PMR, Teixeira JA, Domingues L. Robust industrial Saccharomyces cerevisiae strains for very high gravity bio-ethanol fermentations. J Biosci Bioeng 2011;112:130-6.

[32] Pereira FB, Gomes DG, Guimaraes PMR, Teixeira JA, Domingues L. Cell recycling during repeated very high gravity bio-ethanol fermentations using the industrial Saccharomyces cerevisiae strain PE-2. Biotechnol Lett 2012;34:45-53.

[33] Telmo C, Lousada J. The explained variation by lignin and extractive contents on higher heating value of wood. Biomass Bioenergy 2011;35:1663-7.

[34] Hashemi M, Razavi SH, Shojaosadati SA, Mousavi SM. The potential of brewer's spent grain to improve the production of $\alpha$-amylase by Bacillus sp. KR-8104 in submerged fermentation system. N Biotechnol 2011;28:165-72.

[35] Silva JP, Sousa S, Rodrigues J, Antunes H, Porter JJ, Gonçalves I, et al. Adsorption of acid orange 7 dye in aqueous solutions by spent brewery grains. Sep Purif Technol 2004;40:309-15.

[36] Wilkinson S, Smart KA, James S, Cook DJ. Bioethanol production from brewers spent grains using a fungal Consolidated Bioprocessing (CBP) approach. Bioenergy Res 2017;10:146-57.

[37] Viëtor RJ, Voragen AGJ, Angelino S. Composition of non-starch polysaccharides in wort and spent grain from brewing trials with malt from a good malting quality barley and a feed barley. J Inst Brew 1993;99:243-8.

[38] Gómez B, Míguez B, Veiga A, Parajó JC, Alonso JL. Production, purification, and in vitro evaluation of the prebiotic potential of arabinoxylooligosaccharides from brewer's spent grain. J Agric Food Chem 2015;63:8429-38.

[39] Karimi K, Taherzadeh MJ. A critical review of analytical methods in pretreatment of lignocelluloses: composition, imaging, and crystallinity. Bioresour Technol 2016;200:1008-18.

[40] Jönsson LJ, Martín C. Pretreatment of lignocellulose: formation of inhibitory byproducts and strategies for minimizing their effects. Bioresour Technol 2016;199:103-12.

[41] Carvalheiro F, Fernandes TS, Duarte LC, Lopes S, Moura P, Pereira H, et al. Hydrothermal processing of hardwoods and agro-industrial residues: evaluation of xylo-oligosaccharides production. Proceedings of 2 nd wood nordic biorefinery conference 2009:96-102.

[42] Plaza PE, Gallego-Morales LJ, Peñuela-Vásquez M, Lucas S, García-Cubero MT, Coca M. Biobutanol production from brewer's spent grain hydrolysates by Clostridium beijerinckii. Bioresour Technol 2017;244:166-74.

[43] Ko JK, Kim Y, Ximenes E, Ladisch MR. Effect of liquid hot water pretreatment severity on properties of hardwood lignin and enzymatic hydrolysis of cellulose. Biotechnol Bioeng 2015;112:252-62.

[44] Wallace J, Brienzo M, García-Aparicio MP, Görgens JF. Lignin enrichment and enzyme deactivation as the root cause of enzymatic hydrolysis slowdown of steam pretreated sugarcane bagasse. N Biotechnol 2016;33:361-71.

[45] Modenbach AA, Nokes SE. The use of high-solids loadings in biomass pretreatment-a review. Biotechnol Bioeng 2012;109:1430-42.

[46] Hafid HS, Nor 'Aini AR, Mokhtar MN, Talib AT, Baharuddin AS, Umi Kalsom MS. Over production of fermentable sugar for bioethanol production from carbohydrate-rich Malaysian food waste via sequential acid-enzymatic hydrolysis pretreatment. Waste Manag 2017;67:95-105. 
[47] Agudelo RA, García-Aparicio MP, Görgens JF. Steam explosion pretreatment of triticale $(\times$ Triticosecale wittmack) straw for sugar production. N Biotechnol 2016;33:153-63.

[48] Cunha JT, Aguiar TQ, Romaní A, Oliveira C, Domingues L. Contribution of PRS3, RPB4 and ZWF1 to the resistance of industrial Saccharomyces cerevisiae CCUG53310 and PE-2 strains to lignocellulosic hydrolysate-derived inhibitors. Bioresour Technol 2015;191:7-16.
[49] Costa CE, Romaní A, Cunha JT, Johansson B, Domingues L. Integrated approach for selecting efficient Saccharomyces cerevisiae for industrial lignocellulosic fermentations: importance of yeast chassis linked to process conditions. Bioresour Technol 2017;227:24-34.

[50] Pereira FB, Romaní A, Ruiz HA, Teixeira JA, Domingues L. Industrial robust yeast isolates with great potential for fermentation of lignocellulosic biomass. Bioresour Technol 2014;161:192-9. 